\title{
CONCEPT PAPER FOR RESEARCHING THE PERCEPTIONS OF HIGHER EDUCATION SOCIAL MEDIA SITES: HOW ARE SCHOOL SOCIAL MEDIA SITES ENGAGING DIGITAL NATIVES' COMPARED TO NON-TRADITIONAL STUDENTS?
}

\author{
Kenneth Marsilio, Robert Morris University, kjmst4@mail.rmu.edu
}

\section{INTRODUCTION}

This proposed research will utilize the Theory of Student Involvement to investigate how students' acceptance of social media can affect the students' engagement and motivation. Schools can use social media to market and communicate information to students at a high rate of efficiency and a reduced cost, which has led to recruiting and informing tactics that have more emphasis on using social media (Barnes \& Lescault, 2013). Nontraditional students can have different experiences compared to digital natives or traditional students when it comes to using the social media operated by institutes of higher education. For this study, traditional students are defined as students who attend higher education full time and right after high school. Nontraditional are all other students, typically adults who do not attend higher education full time. Traditional students are being perceived as "digital natives", since they are part of the millennial generation and are more adept at utilizing and understanding technology and information systems, such as social media. The acceptance levels of the "digital natives" or traditional students compared to the nontraditional students could be a significant gap. (Ash, 2015; Marsilio, 2016).

Information systems are not always used by those who can benefit from them. It is vital to be able to manage and direct technology use, in this case, social media usage. This way, organizations can ensure that the information system is implemented and used in the manner that it was intended. There are external factors and internal perceptions that dictate if members of an organization will use the system. One of the prevalent models for investigating the acceptance of an IS system is the Technology Acceptance Model (Almutairi, 2007). Marketing Research has focused on the identifying the perceptions of students to better engage them (Neier \& Zayer, 2015).

\section{LITERATURE REVIEW}

\section{Social Media}

In the last decade, technology has made its entrance into the world of learning. Cilesiz (2010) uses a quote from Jonassen's (1984) research "since experiencing a mediated event is substantively different from direct experience of an event, the resulting phenomena or conscious perceptions must be substantively different" (p. 166). This quote discusses how media alters the way we experience an event. Social media has a distinct impact on the learning environment. Dewey's (1938) learning theory emphasizes that learning takes place in experiences of the individual. Social media can influence individuals' learning experiences by altering their attitudes and preferences through a social media frame. The study of users' experiences with technology in education allows for a comprehensive understanding of social media's effect in the education field (Cilesiz, 2010).

Social media is a means for building relationships between people and organizations. Achen (2015) discusses how organizations market towards their customers and build relationships. This is known as relationship marketing, as the marketing is attempting to influence patrons to build a relationship with the organization. This is an important relationship for students, when students interact with social media accounts, the information reaches more individuals in the students' networks. Social media offers tools that aim to market or promote its uses and for schools, this marketing is aimed at getting students to engage within the school community, events, and other students. However, further research is needed regarding its effectiveness engaging students in the school community (Achen, 2015). 


\section{Social Media in Education}

Literature from Knight, Rochon, and Hailey (2015) provides an initial reflective perspective into using social media to help with the transition into higher education. They stated that students were most likely to focus on interacting and building social academic social media sites. While these were traditional students, social media can engage all students in social networks through education and compensate for the social challenges presented by the transition phase of entering into higher education.

Several forms of social media are being used in education. While students use social media to communicate, faculty use of education curricula creates a mixture of typical in-class educational style and social media to bring social elements into education. Social media is described by Casey and Wells (2015) as an application that allows users to communicate and display their social networks. Social media can be used to perform research, students and librarians both use social media sites to look up information for academic purposes (Kyung-Sun \& Sei-hing, 2016). Social media allows students to build networks that provide an opportunity for meeting other students outside of their own current personal network. Education curricula that use virtual classroom environments, which allow for group discussions encouraging students to learn from their peers, and while educators can oversee the learning process (Casey \& Wells, 2015).

Social Media in Academic Libraries. Further showcasing how social media can be used by organizations to engage its target market, university libraries are using social media to build relationships with their patrons. Social media is providing more tools to connect with library users on a broader basis. Sheikh, Syed, \& Naseer's (2016) research showed that almost $90 \%$ of the libraries in the study have promoted social media tools through their library's websites. It is no surprise that Facebook continues to lead the way in social media sites used by libraries, as Facebook is consistently the top social media site used in the world by the people or organizations. The libraries use Facebook to promote events and attempt to engage its followers in library activities. Sheikh, Syed, \& Naseers (2016) make a statement discussing today's technological environment represents how critical it is for organizations to use social media as part of its marketing plan: "In an environment where the influence of the social media websites are becoming increasingly important, it becomes unavoidable for libraries to develop an on-line communication strategy, which can serve as a resource for stimulation, the provision of services and marketing" (Sheikh, Syed, \& Naseer, 2016, p.53) They argue that it is essential to get feedback on the services provided by the library, to identify opportunities for improvement to the services that could help users (Sheikh, Syed, \& Naseer, 2016)

\section{Digital Natives and Education}

Traditional students are now part of the millennial generation, who are referred to as digital natives. This generation is born and raised in the times of modern technology. They are more capable of using technology. Prensky (2013) argues that it is not just about knowing how to use the technology, it is now about being able to combine technology and its capabilities into the mental process of thinking. This technological mindset of the traditional students has changed the education process. Social media is now considered an instrument for teaching. "The characteristics and learning styles of digital natives often differ greatly from those of their digital immigrant educators" (typically Baby Boomers, Gen Xers, and less frequently Traditionalists) who are designing and delivering the instruction. pg 2). "The largest gap between the generations comes in the area of social networking" (Ash, 2015, p.3).

Social media tied with mobile technology, has increased the ability to learn and promoted communication to new heights for the academic environment. It eliminates the barriers of space and time, by providing a platform of communication that is always open, accessible, and can reach across the world. In the academic world, it permits the creation of innovataive courses and online learning environments (Chai \& Fan, 2016).

\section{Theory of Student Involvement}

Astin (1994) proposes that getting students involved in the campus community will positively impact their education. The more involved a student is in the campus community, the more likely students will be to commit to learning and developing in college. This theory on involvement should be applied to adult learners and other 
nontraditional students through the context of higher education. These groups are typically not involved in the school community. Using Astin's theory of student involvement, it was proposed by Heiberger and Harper (2008) that students who were socially active on social media were more likely to be closer to the school community (Astin, 1994; Achen, 2015).

\section{Problem}

The problem that this proposed research seeks to address is the lack of understanding the difference in perceptions of digital natives and non-traditional students in regards to their use of social media in higher education. Research suggests that non-traditional students may be engaging differently in social media based on their perceptions, as a traditional/mill or nontraditional student. According to Heiberger and Harper's (2008) research, if students' perceptions cause them to not engage socially through social media, they may not be as likely to succeed in higher education.

\section{Purpose}

This purpose of this proposed research would be to identify the acceptance rates of traditional students and nontraditional students in using school social media sites, in terms of their perceived usefulness and ease of use. As well as, to understand if the perceptions of traditional and nontraditional students differ and if it correlates to their usage of school social media sites. The objective would be to add to the literature base on understanding student perceptions in regards to social media. This understanding could provide important data for how schools could better adapt their social media to support two different student populations with varying needs.

\section{METHODOLOGY}

The methodology will be a quantitative study, applying the Technology Acceptance Model (TAM) to measure the perceived usefulness and perceived ease of use of school's social media pages. The TAM theory generated by Davis (1989) is a reliable measurement tool for acceptance. It is an ideal tool for assessing user demand for IT services, such as social media sites run by institutes of higher education.

\section{The Technology Acceptance Model.}

The Technology Acceptance Model (TAM) was chosen by the researcher as the appropriate model to explore this topic. According to Mohd, Ahmad, Samsudin, and Sudin (2011), the Technology Acceptance Model is "specifically designed to study IT-adoption and use to predict and explain user acceptance of IT" (p 554). This model was originally developed to help with marketing product development for potential market segments. TAM breaks down the decision of the user to determine if people will actually use the technology. Which is why this model will be applied in this research, as it will be the appropriate tool to measure student veteran perceptions, use, and acceptance of social media (Mohd, Samsudin, \& Sudin, 2011).

The TAM theory was based on the Theory of Reasoned Actions (TRA) by Fishbein and Ajzen in 1975. TAM and TRA were both models used to predict buying practices for consumers. The TRA originally was used for marketers in an attempt to understand the intent of consumers and if they actually purchased a product. The basis of the TRA model is that the two independent variables will lead to the behavioral intention and the actual behavior. The independent variables are the attitude toward the behavior and the subjective norm. The Attitude toward behavior is described as "the degree in which a buyer has a favorable or unfavorable reaction (evaluation, appraisal, etc.) toward a given behavior" (Gentry \& Calatone, 2012, p 947). Figure 1 depicts the TRA mod and Figure 2 shows the TAM model. These figures illustrate the differences between the two models. 


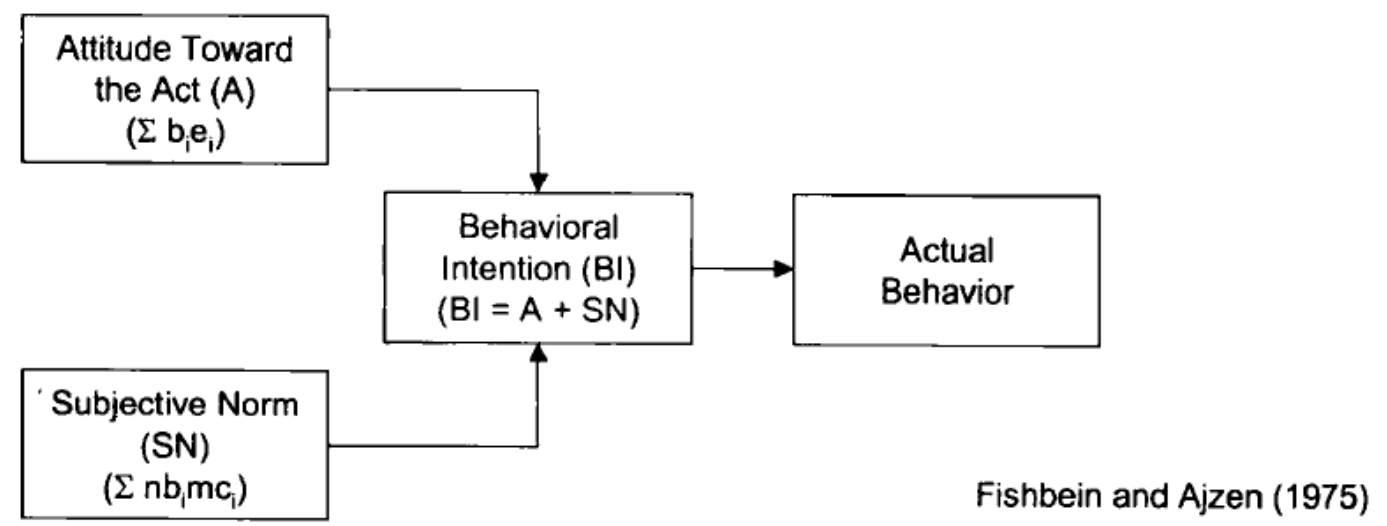

Figure 1. TRA Theory (Fishbein \& Aizen, 1975).

The TAM theory was developed specifically for technology, as the name suggests. It differentiates itself from the TRA by consolidating the external variables and focusing specifically on two variables, perceived usefulness and perceived ease of use. This model also differs from TRA by having the perceived usefulness dictate the Behavioral intention and the perceived ease of use influence the attitude toward the act. Gentry and Calatone compare the TRA, TAM models. The TAM model was shown to be more consistent for use in behavioral intention studies. Which supports the use of the TAM model in this study for looking at behavioral intentions (Gentry \& Calatone, 2002).

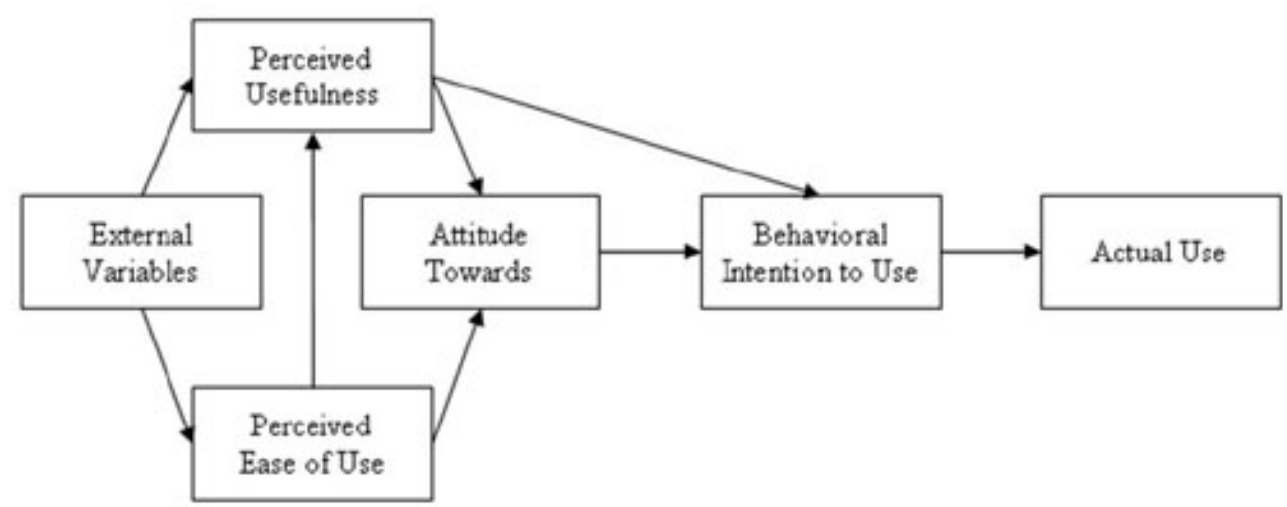

Figure 2. TAM Theory (Davis, 1989).

Also, the TAM theory addresses how culture affects the acceptance of information technology systems. Veiga and Dechant (2001), performed research to identify if cultural beliefs influence the level at which a cultural group will accept IT. They researched Hofstede's cultural dimensions and analyzed if these dimensions would affect how IT would be accepted. These researchers were able to establish that cultural values would influence the acceptance of technology. As student veterans have their own unique subculture within the academic environment, it is important to identify that this culture is a factor in their acceptance of social media (Veiga \& Dechant, 2001).

Social Networks are a specific type of technology that has its own features, and lends itself to be evaluated through the TAM Model. Pinho and Soares (2011) illustrate that student perception of usefulness (PU) and perception of ease of use (PEU) are factors that can be applied to social networks. Pinho and Soares research shows that Facebook is the most popular social networking site, and this is consistent with the TAM models acceptance rate base on PU and PEU, shown by the fact that students perceive it is easy to use and is useful for their goals of communicating (Pinho \& Soares, 2011). 


\section{Research Questions:}

1. How do traditional students' perceptions of social media's usefulness relate to their intentions to use social media?

2. How do nontraditional students' perceptions of social media's usefulness relate to their intentions to use social media?

3. How do traditional students' perceptions of social media's ease of use relate to their use of social media?

4. How do nontraditional students' perceptions of social media's ease of use relate to their use of social media?

5. Do the students' use of school social media sites correlate to their school involvement?

\section{RESEARCH DESIGN}

\section{Research Strategy}

The research strategy that will be implemented in this study will be a quantitative survey. The quantitative survey will be a Likert scale survey based on Davis's TAM model (Davis 1989). There will also be questions on the survey that will probe for demographic information, thus allowing the answers to be analyzed to determine if there is a correlation between the participants' demographic variables and their perceived usage results (Bryman, 2012).

\section{Data Collection Method}

The participants in this proposed study will be student veterans in the Pittsburgh Metropolitan area. The sample for the quantitative data will be a purposive sampling with a criterion sampling. This means that anyone who has the criteria that the researcher is looking for can be sampled. The criteria in this study will only be that the participant is currently attending school in the population area and uses social media. The minimum number that is advised for validity in the quantitative portion of the research is 120, according to Davis's original TAM model article (Davis, 1989; Onwuegbuzie \& Collins, 2007).

\section{Data Analysis}

All data will be input into the SPSS analytical processor by the researcher and verified for accurate input. The frequencies, median, and mean will be processed to present the distribution of the variables. This ordinal data will be analyzed with a spearman correlation analysis to identify the relationship between the variables of perceptions and use. The analysis should show if there are significant differences in perceptions among ages, race, or other demographic characteristics.

\section{CONTRIBUTION TO LITERATURE}

The knowledge created by this study will further the marketing techniques to engage both traditional and nontraditional students with school social media sites based on their perceived usefulness and ease of use. Thus allowing for the potential of both population segments to benefit from the features of school social media sites. This could lead to more involvement in the higher education community and a greater likelihood of academic success.

\section{DISSEMENATION OF KNOWLEDGE}

The knowledge created by this research will be disseminated into academic channels via submission to a related publication and conference hearing. Thereby allowing other researchers the ability to read and apply this knowledge. It will add into the body of literature discussing social media and school engagement. The author will also contact the local offices that work with social media for institutes of higher education to share the findings of this study. 


\begin{abstract}
SUMMARY
Research suggests that students perceive social media differently based on whether or not they are a traditional student or nontraditional student. Students' perceptions are effecting their use of social media and social media use can indirectly influence a student's potential for success in higher education. This research proposes to use the TAM model to identify if the perceptions of students relates to their use. This identification of students' perceptions will be used to establish better methods of social media engagement from institutes of higher education to their students.
\end{abstract}

\title{
REFERENCES
}

Achen, R. (2015). Using Facebook and Twitter to Encourage Physical Activity: Are College Students Connecting With Campus Recreation on Social Media? A Pilot Study.

Almutairi, H. (2007). Is the 'Technology Acceptance Model' universally applicable?: The Case of the Kuwaiti Ministries. Journal of Global Information Technology Management, 10.2, 57-80.

Ash, B. (2015). Using Twitter to Engage Digital Natives. Journal of Applied Research for Business Instruction.13(2).

Astin, (1994). Student involvement: A developmental theory for higher education. Journal of College Student Development, 518-529.

Barnes N. \& Lescault, A. (2013). Higher Ed Documents Social Media ROI: New Communications Tools Are a Game Changer. Journal of New Communications Research. 5(1), 142-145.

Bryman, A. (2012). Social research methods. Oxford University Press Inc.

Casey, G. \& Wells, M. (2015). Remixing to design learning: Social media and peer-to-peer interaction. Journal of Learning Design, 8(1), 38-54.

Chai, J., Fan, K. (2016). Mobile Inverted Constructivism: Education of Interaction Technology in Social Media. Eurasia Journal of Mathematics, 12(5), 1425-1442.

Cilesiz, S. (2010). A phenomenological approach to experiences with technology: current state, promise, and future directions for research. Educational Technology Research and Development, 59(4), 487-510.

Davis, F. (1989). Perceived usefulness, perceived ease of use, and user acceptance of

Information Technology. MIS Quarterly, 13, 319-340.

Dewey, J. (1938). Experience and Education. New York: McMillan.

Fishbein, M. and Ajzen, I. (1975), Belief, Attitude, Intention and Behaviour: An Introduction to Theory and Research, Addison-Wesley, Reading, MA.

Gentry, L. \& Calantone, R. (2002) A comparison of three models to explain shop-bot use on the web. Psychology \& Marketing. 19(11), 945-956.

Heiberger, G. \& Harper, R. (2008). Have you facebooked Astin lately? Using technology to increase student involvement. New Directions for Student Services, 124, 19-35. 
Irani, Z., Dwivedi Y., \& Williams, M. (2009). Understanding Consumer Adoption of Broadband: An Extension of the Technology Acceptance Model. The Journal of the Operational Research Society, 60(10)1322-1334.

Knight, J., Rochon, R., \& Hailey, B. (2015). Lessons learned from four years of using social media to support transition to higher education. Academic Conferences \& Publishing International Ltd, 242-246.

Kyung-Sun, K. \& Sei-Ching, J. (2016). Use and evaluation of information from social media in the academic context: Analysis of gap between students and librarians. The Journal of Academic Librarianship, $42(1), 74-82$.

Marsilio, K. (2016). (Doctoral Dissertation) Retrieved from Robert Morris University, ProQuest, UMI Dissertations Publishing. (Accession Order No. [3646059])

Mohd, F., Ahmad, F., Samsudin, N., \& Sudin, S. (2011). Extending the technology acceptance model to account for social influence, trust and integration, for pervasic computing environment: A case study in university industry. American Journal of Economics and Business Administration, 3.3, 552-559.

Neier, S. \& Zayer L. (2015). Students' Perceptions and Experiences of Social Media in Higher Education. Journal of Marketing Education, 37(3), 133-143.

Onwuegbuzie, A., \& Collins, K. (2007). A typology of mixed methods sampling designs in social science research. The Qualitative Report, 12(2), 281-316.

Pinho, J. \& Soares, A. (2011). Examining the technology acceptance model in the adoption of social networks, Journal of Research in Interactive Marketing, 5(3), 116 - 129.

Prensky, M. (2013). Our brains extended. Educational Leadership, 70(6), 22-27.

Sheikh, A., Ali Syed, K., \& Naseer M. (2016). Pakistan Library \& Information Science Journal, 47(2), 45-55.

Stevens, B. (2012). Knowing is half the battle: How veterans in Southwest Pennsylvania learn and share benefit information, and the role of social media in the process. (Doctoral Dissertation) Retrieved from Robert Morris University, ProQuest, UMI Dissertations Publishing. (Accession Order No. [3646059])

Veiga, J. \& Dechant, K. (2001). Towards modelling the effects of national culture on IT implementation and acceptance. Journal of Information Technology, 16, 145-58. 